The Official Journal of the Kettil Bruun Society for Social and Epidemiological Research on Alcohol

\title{
Addiction: The dance between concept and terms*
}

\author{
Robin Room ${ }^{1,2,3}$, Matilda Hellman ${ }^{4}$, and Kerstin Stenius ${ }^{1,5}$ \\ ${ }^{1}$ Centre for Social Research on Alcohol \& Drugs, Stockholm University, Sweden \\ ${ }^{2}$ Centre for Alcohol Policy Research, Turning Point, Fitzroy, Victoria, Australia \\ ${ }^{3}$ Melbourne School of Population \& Global Health, University of Melbourne, Australia \\ ${ }^{4}$ Centre for Research on Addiction, Control and Governance, Department of Social Research, Faculty of Social Sciences, University of Helsinki, \\ Finland \\ ${ }^{5}$ National Institute for Health and Welfare, Helsinki, Finland \\ *Revised from a paper presented at a Kettil Bruun Society thematic meeting, “Addiction: What Is the Added Value of the Concept Today?” at the \\ Conference Hotel Majvik, Helsinki, Finland, 14-17 October 2012. This work has been partially funded from the European Community's Seventh \\ Framework Programme (FP7/2007-2013), under Grant Agreement no. 266813 - Addictions and Lifestyle in Contemporary Europe - Reframing \\ Addictions Project (ALICE RAP). Participant organizations in ALICE RAP can be seen at http://www.alicerap.eu/about-alice-rap/partners.html. \\ Thanks to Virginia Berridge and an anonymous reviewer for their comments. The authors, of course, take responsibility for the paper's text.
}

\begin{abstract}
The paper discusses the relation between a concept of addiction and the terminology used for its communication, drawing on and analyzing historical citations from the Oxford English Dictionary. The history of words used in English illustrates that terms for a concept change over time, often by an existing word being repurposed. "Addiction" as a term existed prior to the contemporary concept, but with a descriptive meaning that did not carry the explanatory power intrinsic in the modern variant. So its use as a word for the modern conception of the addiction phenomenon was delayed well beyond the emergence of the concept. The experience in English of interplay between concept and terms is discussed in the context of two frames: of influence in both directions between medical and popular concepts and terms, and of cross-cultural variations in the concept and of terms for it.
\end{abstract}

\section{Introduction: The Addiction Concept}

This paper is concerned with the emergence of the addiction concept in everyday thinking and the terms that are used to express and refer to the phenomenon. We focus on how the usage of terms has developed in the English language over the last two centuries. We also consider some issues in the wider frame of the concept and terms in other languages.

The addiction concept involves the idea of habitual heavy consumption. But the concept goes a long step beyond such description; instead, it provides and functions as an explanation for problematic and seemingly illogical behavior. The behavior is not just habitual but determined by forces beyond the actor's control: there is a mysterious underlying compulsion (Room, 1987), a "disease of the will” (Valverde, 1998). Thus, Saunders (2013) identifies the main factor "as an 'internal driving force' to substance use." The crucial point of the concept is not the details of how the behavior and its determinants are characterized, but rather that it adds this explanatory dimension: there is something underlying that is impelling behavior which is otherwise inexplicable.

In medical hands, the addiction concept becomes a diagnosis of a condition of mental disorder, providing an explanation of what underlies the behavior (Freeman, 1989). To describe a state or condition involving habitual heavy consumption as a mental disorder is thus another way of invoking the addiction concept.

As markers of when the concept is being deployed, we will therefore take two alternative minimum indications that go beyond a description in terms of habitual behavior. One is in terms of some indication of mental compulsion or craving; the alternative formulation is the definition of the condition as a mental disorder.

In this discussion, we follow a semiotic tradition that distinguishes between a concept that is the idea of a phenomenon or thing, on the one hand, and the terminology, the words and signs used to express it, on the evidence that the term "addiction" existed before the other (Eco, 1979). In the case of addiction, we offer concept

Correspondence: Robin Room, Address: Turning Point, 54-62 Gertrude St., Fitzroy, Vic. 3065, Australia; Telephone: +61 384138430 ; FAX: +61 3 9416 3420; Email: Robin Room, robinr@turningpoint.org/au

Financial support: This work has been partially funded from the European Community's Seventh Framework Programme (FP7/2007-2013), under Grant Agreement no. 266813 - Addictions and Lifestyle in Contemporary Europe - Reframing Addictions Project (ALICE RAP).

Keywords: addiction, Enlightenment, conceptualization, history of ideas, terminology 
came into everyday use, and that it was not initially used in its central contemporary signification. Conversely, the term "addiction" is not always used today in explanatory mode - that is, to indicate behavior beyond the actor's control-though the explanatory mode dominates. In this paper, the intricate dance between concept and terminology is explored, primarily in the context of the English language, but also with reference to some other European languages.

\section{Addiction as a Post-Enlightenment Concept}

Thirty-seven years ago Harry Levine (1978) published "the discovery of addiction." The paper argued that the concept of addiction "emerged in American popular and medical thought at the end of the eighteenth and beginning of the nineteenth century," initially with respect to alcohol, creating a new "paradigm" or "gestalt" or (in Foucault's terminology) "gaze" of the observer concerning habitual consumption.

Levine's analysis was rooted in the then-emergent tradition of studies of the great shift in the conceptualization of mental illness in roughly the same period. Thus Levine's paper has an epigraph from Foucault's work on this subject (1975) and its title pays homage to Rothman's book The Discovery of the Asylum (1971), concerning developments in the United States in this period. Though it is clear that British doctors" "clinical gaze" on "drunkenness" was discerning an element of compulsion already in the late eighteenth century (Nicholls, 2009, p. 59-72; Ruuska, 2013), Levine's dating of the first emergence of the concept as a common and accepted way of thinking about habitual consumption in the general North American culture, initially applied to alcohol, is still substantially apposite (Ferentzy, 2001). Corroborating evidence of a parallel phenomenon in Britain had been provided a few years before Levine's paper, in an analysis by McCormick (1969) of British fiction. McCormick found that around 1830, alongside descriptions of "the same drinking . . . a as existed 80 years before" were descriptions of "a new and more desperate kind of solitary, tragic and inexplicable drinking."

\section{Terms in English for the Concept}

While Levine's paper describes clearly the emergence of a concept and the logic behind it, at a certain point in North American history, he does not point to the use of any particular term for it. $^{1}$ The words and phrases Levine reports being used concerning the emergent concept in the half-century after 1800 include "paroxysms" of drunkenness, the "necessity" to drink, as contrasted with "free agency," a "burning withering desire for drink," a desire which was "overwhelming," "overpowering," and "irresistible." While the concept became commonly

\footnotetext{
${ }^{1}$ In a later paper, Levine (1981) considers the rich vocabulary of terms in English for drunkenness. The myriad of terms listed in it is almost devoid of terms that imply the addiction concept, "dipsomaniac" and "dipso" being exceptions, and in some senses "alcoholic” and "alcoholist.”
}

understood, there was seemingly not a clear and single term attached to it.

There are a number of terms in English that have become associated with the concept over the last two centuries. Some, like "addiction," “dependence," or "inebriety,” also had a variety of other meanings and existed in English with these meanings before becoming used also to express the addiction concept that concerns us here. Others, like "narcomania," "dipsomania," and "morphinomania," were new terms invented for the purpose by medical writers. "Alcoholic" and "alcoholism" is a mixed case: "alcoholic" has a variety of other meanings, but then "alcoholism" came into use primarily in a medical meaning in the midnineteenth century. It was an Englishing of a Latin term, alcoholismus chronicus, put forward by a Swedish doctor, Magnus Huss, in a monograph originally published in Swedish (Huss, 1849-51). But Huss's meaning for the term was not in terms of the addiction concept, but rather, as the Medical Temperance Journal noted in 1882, was applied to "cases which come directly from the toxic action of alcohol" (quoted for "alcoholism" in the Oxford English Dictionary) - in other words, in what Ruuska (2013) terms the emergent "consequences problematic" as a medical view, rather than the "behavioural problematic" which included the addiction concept. Huss's meaning, oriented to long-term physiological consequences, persisted in medical nosology through the 1940 s, so that, for instance, the title of a book edited by Jellinek (1942) early in his career as an alcohol scholar was Alcohol Addiction and Chronic Alcoholism, as two separate concepts. As we shall see, there are precedents back to the nineteenth century for "alcoholism" and "alcoholic" to refer to an addiction concept, but this meaning only became dominant after the rise of Alcoholics Anonymous.

\section{Charting the Dance between Concept and Terms in English}

The primary reference source for the historical development of words and their meanings in the English language is what is now called the Oxford English Dictionary, which aims to capture and define every word used in English since the year 1000. Originating as a major project and product of nineteenth-century philology (Murray, 1977), the dictionary first appeared piece by piece between 1884 and 1928 and was originally called the New English Dictionary on Historical Principles, a title that reflected its strong orientation to the history not only of words but also of their meanings and use. The OED, as it is often affectionately called, is now available by subscription online and continuously updated.

The OED makes an effort to distinguish different senses of a word in a systematic way and to give quotations from a diversity of written sources exemplifying the development of every sense of the word. Its attention to different senses of a word makes it a useful resource for tracing the interplay between the concept of addiction and the words used for it in English. But the OED also has some limits for this purpose. It is a lexicographical exercise, and the volunteers and editors whose work it reflects are not 
necessarily experts in the particular topic surrounding a word and a sense. The quotations are chosen to be representative of meanings, particularly new meanings, at different periods in the word's history, but the selection is crucially dependent not only on the lexicographer making or revising the entry but also on the raw material of quotations collected by volunteer readers, often long ago, making their way through their agreed part of the enormous corpus of publications in English. What struck a reader as interesting and worth copying and sending in is not necessarily what a specialist collecting materials for a study of a specific area-such as the addiction concept-would have chosen. The OED's historical citations are thus by no means a complete record. The emphasis of the lexicography is on when a new word or meaning (or spelling) emerges, and the citations chosen emphasize such changes or additional usages more than stability. OED citations should thus not be taken as indicating much about frequency of usage.

Keeping these limitations in mind, the $O E D$ is still a useful resource for our purposes. Table 1 assembles quotations from it for the words (phrases in the case of "dependence" and its variants) when used in the sense of the addiction concept or in senses related to it. In particular, it includes (in parentheses) earlier uses that seemed to us not to clearly go beyond the sense of heavy habitual use- that is, not to fulfill our criteria for the characteristics of the contemporary addiction concept, with its explanatory burden.

It will be seen that "addict" and its derivatives were in use in English well before the post-Enlightenment period Levine's paper focuses on. We have given quotations the $O E D$ puts under the sense of addiction to a substance, but they are consonant with a broader set of meanings around "committed," "devoted," or "attached," which the OED arranges into six other senses of "addicted." A line from Shakespeare's Twelfth Night, for instance, is quoted for one of these senses: "Being addicted to a melancholy as she is." One clear lesson from the $O E D$ is that the broader use of "addicted" and "addiction" beyond alcohol and drugs in recent decades, discussed below, is by no means a novelty in English, although the application of the full modern addiction concept to a wider range of behaviors may be.

"Addict" and "addiction," and compound terms such as "alcohol addiction" and "drug addiction," are used from the 1880s onward to refer to the addiction concept, with the $O E D$ giving a citation for each from the last 10 years. Despite considerable flux in professional terminology (Room, 1998), “addiction” has remained a strong choice for reference to the addiction concept for well over a century.

The first quotation with a derivative of "addict" that we have classed as used in the sense of an explanatory compulsion is from 1837. By this time, an alternative cluster of words was being used, primarily referring to alcohol: inebriety and its derivatives, referring to overuse and its consequential states. These words were originally used in English as an equivalent of "drunk" but were often used figuratively; thus the oldest citation in the $O E D$, from
1497, describes the biblical Peter "as a man inebryat in the loue [love] of God." It seems to have been an initiative from medicine to apply "inebriate" within an addiction concept; thus the first such citation, from 1864, is a reference to the Asylum for Inebriates which had just opened in Binghamton, New York (Baumohl \& Room, 1987). As the citations suggest, "inebriety" in the context of psychoactive substances, particularly alcohol, became a semi-technical medical term in the late nineteenth century. The usage was often ambiguous with regard to whether a meaning within the addiction concept was intended. The period of medical usage left behind a residue in the longer term in legal language: for example, "inebriates act" (law on treatment for addiction) and "public inebriate" (a person frequently drunk in public). Though the OED does not pick this up, such legal phrases are the primary contexts for current usage of the terms.

In the later nineteenth century, a wave of medical attention to addiction issues produced several neologisms. "Dipsomania" is first recorded in the OED in 1843, equated at that time with "drunkenness," but with a notation that dipsomania "is regarded as a temporary form of insanity." A citation from 1862 describes that a woman "had been for many years excessively given to drinking, and in her case it had developed to actual 'dipsomania,"” but without further specification of the meaning of dipsomania. The term "mania" (borrowed from Medieval Latin) is first recorded in the OED in 1398, meaning "excessive desire," and having from the first a connotation of mental illness. As a Latin-derived term, it became a common component of new combined forms in medical terminology, as the $O E D$ notes, "forming nouns referring to kinds of mental illness, desires, and passions marked by wild excess or delusion."

It was Norman Kerr, the foremost British addiction doctor of his time, who proposed the term "narcomania," with a central meaning of an uncontrollable craving for psychoactive substances. ${ }^{2}$ It has primarily been used more broadly to signify an addicted condition, as in the title of later editions of Kerr's magnum opus, Inebriety, or Narcomania (1894). The OED gives citations from 1976 and 1996, but the term is not in common use today. The latest citation for "dipsomania" in the $O E D$ is from 1883; the $O E D$ does not pick up that the term is still in some contemporary use, primarily as a comic term describing an "amiable" habitual heavy drinker, as in the 1950 film Harvey and its offshoots (Reed, 2012). The OED also misses the term "euphomania," coined in Danish in 1944 as amphetamines and morphine became more widely used in wartime (Houberg, 2014) and occasionally used as a term in English-language Nordic papers (e.g., Anchersen, 1947).

\footnotetext{
${ }^{2}$ While the $O E D$ gives the date 1865 for this, with the reference "Inebriety ii. 34," the reference appears to be to the first edition of Kerr's book, in 1888.
} 
Table 1

Expressions of the Addiction Concept in English -- Abbreviated quotations from the Oxford English Dictionary, http:///www.OED.com, as of September 22, 2012

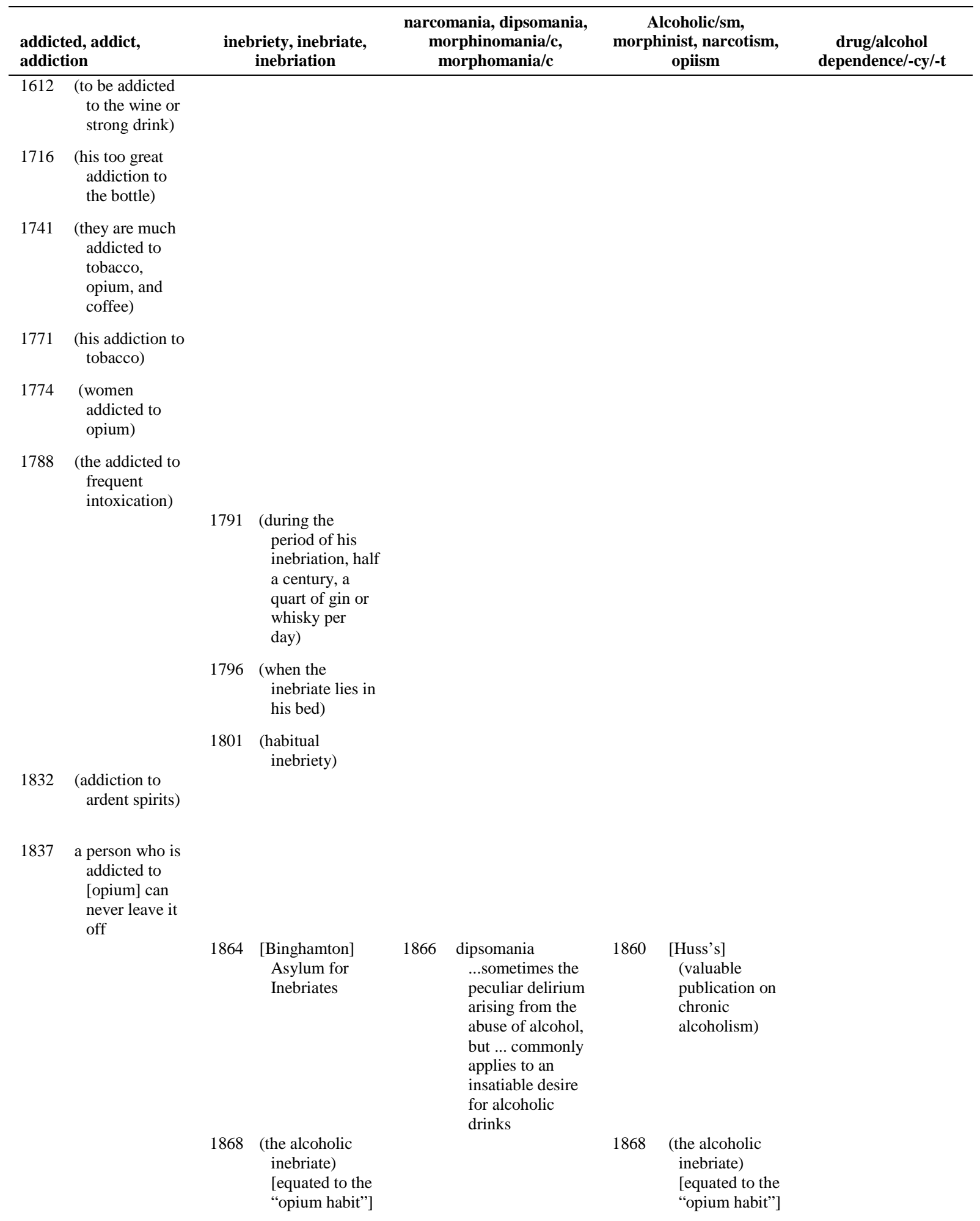




\begin{tabular}{|c|c|c|c|c|c|c|c|c|c|}
\hline \multicolumn{2}{|c|}{$\begin{array}{l}\text { addicted, addict, } \\
\text { addiction }\end{array}$} & \multicolumn{2}{|c|}{$\begin{array}{l}\text { inebriety, inebriate, } \\
\text { inebriation }\end{array}$} & \multicolumn{2}{|c|}{$\begin{array}{c}\text { narcomania, dipsomania, } \\
\text { morphinomania/c, } \\
\text { morphomania/c }\end{array}$} & \multicolumn{2}{|c|}{$\begin{array}{c}\text { Alcoholic/sm, } \\
\text { morphinist, narcotism, } \\
\text { opiism }\end{array}$} & \multicolumn{2}{|c|}{$\begin{array}{c}\text { drug/alcohol } \\
\text { dependence/-cy/-t }\end{array}$} \\
\hline 1881 & $\begin{array}{l}\text { family history } \\
\text { of alcoholism, } \\
\text { drug } \\
\text { addiction, } \\
\text { insanity }\end{array}$ & 1881 & $\begin{array}{l}\text { Dipsomania, or } \\
\text { inebriety, is a } \\
\text { fundamental } \\
\text { disease of the } \\
\text { nervous system }\end{array}$ & 1881 & $\begin{array}{l}\text { Dipsomania, or } \\
\text { inebriety, is a } \\
\text { fundamental } \\
\text { disease of the } \\
\text { nervous system }\end{array}$ & 1881 & $\begin{array}{l}\text { family history } \\
\text { of alcoholism, } \\
\text { drug } \\
\text { addiction, } \\
\text { insanity }\end{array}$ & & \\
\hline 1886 & $\begin{array}{l}\text { (opium habit } \\
\text { [but] alcohol } \\
\text { addiction) }\end{array}$ & & & 1883 & $\begin{array}{l}\text { dipsomania ... } \\
\text { distinct from } \\
\text { ordinary and } \\
\text { habitual } \\
\text { drunkenness ... } \\
\text { craving is } \\
\text { paroxysmal }\end{array}$ & 1889 & $\begin{array}{l}\text { (unmistakable } \\
\text { tokens of the } \\
\text { torpor of } \\
\text { opiism) }\end{array}$ & & \\
\hline \multirow[t]{4}{*}{1889} & $\begin{array}{l}\text { Alcohol and } \\
\text { drug } \\
\text { addictions } \\
\text { cured [ad. in } \\
\text { NY Times] }\end{array}$ & & & 1887 & $\begin{array}{l}\text { The diagnosis of } \\
\text { morphinomania }\end{array}$ & & & & \\
\hline & & & & 1888 & $\begin{array}{l}\text { narcomania ... this } \\
\text { abnormal state, } \\
\text { especially in its } \\
\text { marked maniacal } \\
\text { form }\end{array}$ & & & & \\
\hline & & 1893 & $\begin{array}{l}\text { inebriety is a } \\
\text { disease of the } \\
\text { nervous system }\end{array}$ & 1898 & $\begin{array}{l}\text { transformed the } \\
\text { dipsomaniac and } \\
\text { morphinomaniac } \\
\text { into self- } \\
\text { controlled and } \\
\text { useful members } \\
\text { of society. }\end{array}$ & 1894 & $\begin{array}{l}\text { A very short } \\
\text { time suffices } \\
\text { for the } \\
\text { establishment } \\
\text { of “opiism” }\end{array}$ & & \\
\hline & & & & 1899 & $\begin{array}{l}\text { the so-called } \\
\text { dipsomaniac or } \\
\text { morphinomaniac }\end{array}$ & 1894 & $\begin{array}{l}\text { dipsomaniacs, } \\
\text { morphinists } \\
\text { and epileptics }\end{array}$ & & \\
\hline 1901 & $\begin{array}{l}\text { Imaginary pains } \\
\text {... of addicts ... } \\
\text { an excuse for } \\
\text { taking their } \\
\text { accustomed } \\
\text { drug }\end{array}$ & & & & & 1897 & $\begin{array}{l}\text { (The children of } \\
\text { three } \\
\text { morphinist } \\
\text { mothers were } \\
\text { fairly healthy) }\end{array}$ & 1901 & $\begin{array}{l}\text { drug } \\
\text { dependence }\end{array}$ \\
\hline \multirow[t]{4}{*}{1906} & alcohol addict & & & 1909 & $\begin{array}{l}\text { dipso and } \\
\text { narcomania are } \\
\text { definite maladies }\end{array}$ & 1909 & $\begin{array}{l}\text { “chronic } \\
\text { alcoholic,” } \\
\text { and must have } \\
\text { a bottle of port } \\
\text { a day }\end{array}$ & 1904 & $\begin{array}{l}\text { drug } \\
\text { dependent }\end{array}$ \\
\hline & & & & 1912 & $\begin{array}{l}\text { He’s just short of a } \\
\text { raving } \\
\text { morphomaniac }\end{array}$ & 1910 & $\begin{array}{l}\text { [title:] The } \\
\text { modern } \\
\text { treatment of } \\
\text { alcoholism } \\
\text { and drug } \\
\text { narcotism }\end{array}$ & & \\
\hline & & & & & & & & 1946 & $\begin{array}{l}\text { alcohol } \\
\text { dependency }\end{array}$ \\
\hline & & & & & & & & 1957 & $\begin{array}{l}\text { alcohol } \\
\text { dependence }\end{array}$ \\
\hline
\end{tabular}

Quotations are shown that use the listed terms concerning habitual heavy use; those expressing the addiction concept—identified as a mental disease or with an element of compulsion-are shown without parentheses 
"Alcoholic" and "alcoholism" were clearly in use, particularly in temperance writing, by the mid-nineteenth century. A citation from an 1848 allegorical temperance tale (Cowen, 1848) shows the first recorded usage of "alcoholism" but in the sense of all who are on the side of Emperor Alcohol the Great in the battle against temperance forces. Otherwise, early usage is primarily for habitual heavy drinking or with reference to the usage by Magnus Huss. Thus the OED gives a citation from 1868 that equates the stigmatization of an "alcoholic inebriate" with that of someone with an "opium habit." An 1881 citation, however, puts "alcoholism" in a list of conditions with "drug addiction" and "insanity," and a couple of early twentieth-century citations use "alcoholic" or "alcoholism" within the frame of the addiction concept, long before the switch in official medical nosology in the late 1940s.

The nosological switch to "drug dependence" as preferred over "addiction" in professional circles was initiated by a 1963 World Health Organization (WHO) Expert Committee on Drug Dependence (WHO, 1964), with "alcohol dependence" following along in the 1970s (Edwards \& Gross, 1976). The new wording was substituted to cover the retreat from an earlier committee's untenable attempt to confine "addiction" to drugs that were covered by the international drug treaties (Room, 1998). The choice of word involved an extension beyond a technical meaning of "dependence" in psychopharmacology ("dependence-producing” means that a regular user of a drug will experience withdrawal symptoms on stopping - a meaning that is not recognized in the $O E D$ ). But "dependence” and its derivatives have a wide variety of other meanings recorded in the $O E D$, some of them with derogatory connotations that might well carry over to drug users (Fraser \& Gordon, 1994). The usage of "dependence" and "dependency" to refer to the addiction concept is not recognized by the $O E D$ under the terms themselves, but some relevant citations show up in the many compounds (two-word phrases) the OED notes with drug or alcohol as the first word.

\section{Concept and Term: an Intricate Dance}

While, as we have noted, there were precursors, it was primarily in the early nineteenth century that English speakers formed the conceptual understanding of habitual psychoactive substance use that we have called here the concept of addiction. As is presumably common when a new conception is being formed, there was no clearly available semiotic convention for how the concept was to be expressed (Eco, 1979, p. 17). This is apparent from the variety of ad hoc constructions Levine quotes from the period.

One term, "addict," along with its derivatives, was available in English with a meaning, heavy habitual use, that was related to the intended meaning but that did not at the time convey the explanatory power of the concept. It was not until 1837 that a citation could be found in the $O E D$ where it is clear that "addicted" is used with the full weight of inability to control use. In the second half of the nineteenth century, as noted, a number of other terms were invented or put into use to convey the concept.
Eventually, the old connotation of "addiction" as simply describing habitual heavy use was lost, and after the 1880s the term was redeployed with the new meaning signifying the addiction concept-taking on its modern function of serving as an explanation (Room, 2003). We can hypothesize that it was this lack of explanatory power in the meaning of "addiction" in the early nineteenth-century English-speaking world that explains why the word was not much resorted to in the early years of the addiction concept. A "burning withering desire" invoked the explanatory power of the concept much more vividly than a word used to describe habitual behavior. Only when the concept had become well established in the culture, in the historical circumstances explicated by Levine (1978), when alienists and other doctors were picking up the concept and using it as an explanation rather than a simple description of behavior, did it become workable to revert to applying the existing word in a new sense.

However, a variety of other terms continued to compete with it, particularly concerning alcohol addiction. Reflecting the chasm between alcohol and drugs imposed in thinking about them in the middle of the twentieth century, as Courtwright (2005) has documented in the United States, for some decades "alcoholism" and its derivatives took precedence over "addiction," specifically for alcohol. In the latter part of the twentieth century, the psychiatric and nosological establishment made efforts to substitute "dependence" for both "addiction" and "alcoholism," but this shift in terminology has had only limited success in changing English-language popular and media discourse.

\section{Is There a Common Concept across Languages?}

Conceptualizations of addiction problems, and the political and other forces that influence them, are bound to particular social milieus (e.g., Raikhel \& Garriott, 2013). Language use surrounding addiction shapes how we think about the matters it refers to, and it also reflects differences in views between different cultures. It seems that the word "addiction" has mostly been used in the Anglo-American world. Italian, Polish, and Finnish are examples of languages that have had no exact equivalent for the term "addiction" but have primarily made do with other words closer to "dependence" or "misuse” in English.

The linguist Guy Deutscher (2010) contradicts the claim that when a language has no word for a concept, its speakers are unable to understand the concept in question. However, and intriguingly enough, he has shown that what is not present in a language is likely to be something that the speakers in that culture may not have been obliged to think about to a great extent. In the case of the Nordic countries, for instance, historically there has not been a need to rely on a formulation in terms of a disease of the individual will to provide a justification for society and the state to act upon social alcohol and drug problems (Palm \& Stenius, 2002). Although the Anglo-American concept of addiction has made a prominent entry into popular lay speech in recent years in Finland, for example (Hellman, 2010), a comparison between popular media narratives in the United States and in Finland still shows rather crucial 
differences in how the addiction phenomenon is conceptualized in the two societies (Hellman \& Room, 2014).

It is clear that, as a concept in everyday use, addiction presupposes a good deal. Nicholls (2009, p. 59-72) shows how the idea is set within the frame of Enlightenment thinking. Ethnographic studies suggest that it should be viewed also as a post-industrial concept. Thus Kunitz and Levy report that the alcoholism concept only became current in Navajo culture as the idea of time as "spent" and responsibilities measured by the clock took hold:

As the society changes, however, [habitual drunkenness] increasingly come[s] to be seen as maladaptive to the new world where people are expected to be at work on time; where no network of kin is available to help when a husband is out drinking; where bills must be paid; and where all sorts of obligations the dominant society takes for granted must be fulfilled. . . . The drinker's behavior comes to be defined as sick. He is no longer a man who drinks a lot; he is an alcoholic. (1974)

Despite the global diffusion of "Western" ideas through professional channels and popular culture, it is clear that there are still cultural variations in thinking about drug and alcohol intoxication and use (Room, 2006). Even within the narrower cultural range of European societies, there is a wide variety of concepts and terms, and different dances between concept and terminology in different languages. Until the last twenty years or so, for instance, it could be said that neither Swedish nor Finnish popular language distinguished between heavy use and addiction; in Swedish, for instance, missbruk (misuse) tended to be used to cover both concepts.

\section{“Addiction” as a New Common Denominator?}

Starting in the 1980s the addiction concept, with "addiction" as probably the most common term, has expanded its reach in English to cover a wide variety of other habitual behaviors. The spread and enlargement of scope of both "addiction" as a term and the addiction concept as an idea can be viewed as part of larger sociological trends of globalization and the emergence and diffusion of individualization, "risk society," and new media formats across societies and languages (Alexander, 2008; Furedi, 2004; Sedgwick, 1992).

If a 15-year-old spends endless hours on his computer or other electronic gear, "he must be addicted" is offered as the explanation - an explanation that points to particular paths of remediation. The use of the concept and term has expanded in English even to refer to groups and societiesWhen Society Becomes an Addict was the title of a popular U.S. book with a theory of codependence (Schaef, 1988), and it has become a commonplace to describe industrial societies as addicted to oil (Room, 1992). These trends have been picked up in other languages, even where "addiction" or a derivative of it had not been common in the language. So in both French (Saïet, 2011) and Finnish (Hellman, 2010), for instance, discussions can now be found where "addiction" is routinely used for the expanded territory of gambling, sexuality, internet use, and so onalthough not so much concerning the "home territory" of the concept in English, psychoactive substance use, where existing terms in the language tend to remain in use.

Ironically, trends in American psychiatric thinking point to a similar trend at least in professional terminology in English. The newly adopted $5^{\text {th }}$ revision of the Diagnostic and Statistical Manual of the American Psychiatric Association (DSM-5) has renounced the term "dependence" in its general meaning, intending to reserve it for its original technical physiological meaning referring to drug withdrawal symptoms (O’Brien, 2011). Instead, the general term replacing it is to be "substance use disorder"-a term that carries little of the explanatory power of an addiction concept. However, against the wishes of the specialist field's representatives, a derivative of "addiction" is included in the title of the general DSM-5 chapter "Substance-related and addictive disorders" (Hasin et al., 2013) to convey that the chapter also includes "Gambling disorder" (formerly "Pathological gambling”) and will eventually include other "addictive" behavioral disorders. Taken literally, DSM-5 thus applies addiction terminology to other behavioral disorders but not to the "substance use disorders."

But DSM's switch to "use disorders" and avoidance of the terms "addiction" or "dependence" in reference to the disorder may carry little weight in popular thinking. The concept of addiction "belong[s] to the culture as well as to psychiatrists or researchers” (Room, 1989), and the record of use both of terms and of the concept in English reflects some differences in usage between doctors and the general culture, and also that influence operated in both directions.

\section{The Future of the Addiction Concept}

In the present era, the development and fate of the addiction concept seems double-sided. On a philosophical basis, it is argued that "the idea that addictive behaviour is compulsive is logically incoherent" (Heather, 2014); on a pragmatic basis, it is argued that focusing on heavy use and the problems it brings renders an addiction concept superfluous (Rehm et al., 2013). As we have noted, the American Psychiatric Association seems to have abandoned addiction-oriented terminology in describing “disorders" from psychoactive substance use.

On the other hand, at the level of popular culture, the addiction concept remains strong and has even extended its scope, as in the developments we have noted in French and Finnish. The popular demand to discover the "causes of addiction" drives much of the scientific funding in the alcohol and drug fields, even though the practical advances in curing and caring from biomedical science have primarily come from the "consequences problematic" rather than the "behavioural problematic." In modern societies-committed on the one hand to consciousness, attention, and conscientiousness in major social roles, and on the other hand to free markets for consumer preferences as shaped by promotional enticements (Room, 2011) - the addiction concept functions as a comforting explanation, 
resolving the social system's contradictions by pointing to a postulated defect in the individual, a failure in the expectation of self-control. It has been suggested that through the idea of addiction, human beings "understand what it means to be free" (Martin, 2013). As such, this explanatory concept is likely to remain in strong demand.

\section{References}

Alexander, B. (2008). The globalisation of addiction. Oxford, England: Oxford University Press.

Anchersen, P. (1947). On the prognosis of narcomania (euphomania) (to clarify some problems of narcomania). Acta Psychiatrica et Neurologica, 22(34), 153-193.

Baumohl, J., \& Room, R. (1987). Inebriety, doctors and the state: Alcoholism treatment institutions before 1940. In M. Galanter (Ed.), Recent developments in alcoholism (Vol. 5, pp. 135-174). New York, NY, United States: Plenum.

Courtwright, D. T. (2005). Mr. ATOD’s wild ride: What do alcohol, tobacco, and other drugs have in common? Social History of Alcohol and Drugs, 20, 105-140.

Cowen, J. (1848). The first and last days of Alcohol the Great, in the empire of Nationolia: Or, Manxman's records of the temperance revolution. Providence, RI, United States: B. T. Albro.

Deutscher, G. (2010). Through the language glass: Why the world looks different in other languages. New York, NY, United States: Metropolitan Books, Henry Holt and Company.

Eco, U. A. (1979). Theory of semiotics. Bloomington, IN, United States: University of Indiana Press.

Edwards, G., \& Gross, M. M. (1976). Alcohol dependence: Provisional description of a clinical syndrome. British Medical Journal, 1, 1058-1061.

Ferentzy, P. (2001). From sin to disease: Differences and similarities between past and current conceptions of chronic drunkenness. Contemporary Drug Problems, 28(3), 363-390.

Foucault, M. (1975). The birth of the clinic: An archaeology of medical perception. New York, NY, United States: Vintage.

Fraser, N., \& Gordon, L. A. (1994). Genealogy of dependency: Tracking a keyword of the U.S. welfare state. Signs, 19(2), 309-366.

Freeman, A. (1989). Diagnosis as explanation. Early Child Development and Care, 44, 61-72.

Furedi, F. (2004). Therapy culture: Cultivating vulnerability in an uncertain age. London, England, and New York, NY, United States: Routledge.

Hasin, D. S., O’Brien, C. P., Auriacombe, M., Borges, G., Bucholz, K., Budney, A., . . . Grant, B. F. (2013). DSM-5 criteria for substance use disorders: Recommendations and rationale. American Journal of Psychiatry, 170, 834-851.

Heather, N. (2014, June). Addiction as a form of akrasia. Paper presented at the 40th Annual Alcohol Symposium of the Kettil Bruun Society for Social and Epidemiological Research on Alcohol, Torino, Italy.
Hellman, M. (2010). Construing and defining the out of control: Addiction in the media (Doctoral dissertation). University of Helsinki: Swedish School of Social Science.

Hellman, M., \& Room, R. (2014). What's the story on addiction? Popular myths in the USA and Finland. Critical Public Health. Advance online publication. doi:10.1080/09581596.2014.926308

Houberg, E. (2014). Concepts and institutions in Danish drug treatment. Nordic Studies on Alcohol and Drugs, 31(5-6), 527-550.

Huss, M. (1849-51). Alcoholismus chronicus eller chronisk alkoholssjukdom: ett bidrag till dyskrasiernas kännedom; enligt egen och andras erfarenhet [Alcoholismus chronicus or chronic alcohol disorder: a contribution to the study of dyscrasias; based on my own and others' experience]. Stockholm: Beckman.

Jellinek, E. M. (Ed.). (1942). Alcohol addiction and chronic alcoholism. New Haven, CT, United States: Yale University Press.

Kerr, N. S. (1888). Inebriety, its etiology, pathology, treatment and jurisprudence. London, England: H. K. Lewis.

Kerr, N. S. (1894). Inebriety, or narcomania: Its etiology, pathology, treatment and jurisprudence (3rd ed.). London, England: H. K. Lewis.

Levine, H. G. (1978). The discovery of addiction: Changing conceptions of habitual drunkenness in America. Journal of Studies on Alcohol, 39, 143-174.

Levine, H. G. (1981). The vocabulary of drunkenness. Journal of Studies on Alcohol, 42(1), 1038-1051.

Kunitz, S. J., \& Levy, J. E. (1974). Changing ideas of alcohol use among Navaho Indians. Quarterly Journal of Studies on Alcohol, 35, 243-259.

Martin, E. (2013). Following addiction trajectories. In E. Raikhel \& W. Garriott (Eds.), Addiction trajectories (pp. 284-292). Durham, NC, United States and London, England: Duke University Press.

McCormick, M. (1969). First representations of the gamma alcoholic in the English novel. Quarterly Journal of Studies on Alcohol, 30(4), 957-980.

Murray, K. M. E. (1977). Caught in the web of words: James A. H. Murray and the Oxford English Dictionary. New Haven, CT, United States: Yale University Press.

Nicholls, J. (2009). The politics of alcohol: A history of the drink question in England. Manchester, England, and New York, NY, United States: Manchester University Press.

O’Brien, C. (2011). Addiction and dependence in DSM-V. Addiction, 106, 866-867.

Palm, J., \& Stenius, K. (2002). Sweden: Integrated compulsory treatment. European Addiction Research, 8(2), 69-77.

Raikhel, E., \& Garriott, W. (Eds.). (2013). Addiction trajectories. Durham, NC, United States and London, England: Duke University Press.

Reed, R. (2012, June 19). Harvey: Sitcom star Parsons takes a break from Hollywood and vacations down the rabbit hole. New York Observer. Retrieved from http://observer.com/2012/06/harvey-rex-reed-jimparsons/ 
Rehm, J., Marmet, S., Anderson, P., Gual, A., Kraus, L., Nutt, D., .. . Gmel, G. (2013). Defining substance use disorders: Do we really need more than heavy use? Alcohol \& Alcoholism, 48(6), 633-640.

Room, R. (1987). Bring back inebriety? British Journal of Addiction, 82, 1064-1068.

Room, R. (1989). Drugs, consciousness and self-control: Popular and medical conceptions. International Review of Psychiatry, 1, 63-70.

Room, R. (1992). "Healing ourselves and our planet”: The emergence and nature of a generalized twelve step consciousness. Contemporary Drug Problems, 19, 717-740.

Room, R. (1998). Alcohol and drug disorders in the International Classification of Diseases: A shifting kaleidoscope, Drug and Alcohol Review, 17, 305-317.

Room, R. (2003). The cultural framing of addiction. Janus Head, 6, 221-234. Retrieved from http://www.janushead.org/6-2/room.pdf

Room, R. (2006). Taking account of cultural and societal influences on substance use diagnoses and criteria. Addiction, 101(Suppl. 1), 31-39.

Room, R. (2011). Addiction and personal responsibility as solutions to the contradictions of neoliberal consumerism. Critical Public Health, 21(2), 141-151.

Rothman, D. J. (1971). The discovery of the asylum: Social order and disorder in the new republic. Boston, MA, United States: Little, Brown.

Ruuska, A. (2013). Consequences and behaviour problematized: The establishment of alcohol misuse as an object of empirical inquiry in late $18^{\text {th }}$ - and early $19^{\text {th }}$-century European medicine. Nordic Studies on Alcohol and Drugs, 30(1-2), 13-32.

Saïet, M. (2011). Les addictions [The addictions]. Quesais-je? Series No. 3911. Paris, France: Presses Universitaires de France.

Saunders, J. (2013). The concept of substance use disorders: A commentary on 'Defining substance use disorders: Do we really need more than heavy use' by Rehm et al. Alcohol and Alcoholism, 48(6), 644-645.

Schaef, A. W. (1988). When society becomes an addict. San Francisco, CA, United States: Perennial Library.

Sedgwick, E. K. (1992). Epidemics of the will. In J. Crary \& S. Kwinter (Eds.), Incorporations: Zone 6 (pp. 582595). New York, NY, United States: Urzone, Inc.

Valverde, M. (1998). Diseases of the will: Alcohol and the dilemmas of freedom. Cambridge, England: Cambridge University Press.

World Health Organization. (1964). Expert committee on addiction-producing drugs. Thirteenth Report. World Health Organization technical report series no. 273. Geneva, Switzerland: World Health Organization. 